\title{
Three new cases of oculodentodigital (ODD) syndrome: development of the facial phenotype
}

\author{
M A PATTON* ANDKM LAURENCE† \\ From * the Department of Clinical Genetics, The Hospital for Sick Children, Great Ormond Street, London \\ WC1N 3JH; and the Department of Child Health, Welsh National School of Medicine, Cardiff, Wales.
}

SUMMARY Three new cases of oculodentodigital (ODD) syndrome are reported. The clinical $\stackrel{\sim}{\sim}$ features are discussed and the development of the characteristic facial appearance is illustrated. in Conductive deafness is reported in one of our cases and has been reported in six previous cases. It $\stackrel{\infty}{\infty}$ is suggested that it is a feature of the syndrome which is amenable to treatment.

In 1920 Lohmann $^{1}$ described the condition of microphthalmia, hypoplastic nasal alae, syndactyly, and enamel hypoplasia in two unrelated patients. In 1957 Meyer-Schwickerath et $a l^{2}$ introduced the term 'dysplasia oculodentodigitalis'. It remains a rare syndrome with fewer than fifty published case reports. $^{3}$

This report describes the features seen in three patients referred to the genetic counselling clinic.

\section{Case reports}

CASE 1

This patient was the only child of healthy unrelated parents. At the time of her birth her father was 33 years old and her mother was 35 years old. The pregnancy was uncomplicated. Her birth weight was $3.6 \mathrm{~kg}$. At birth she was found to have syndactyly of the third, fourth, and fifth fingers on the left, and of the fourth and fifth fingers on the right. Radiological examination revealed absence of the middle phalanx of the fifth digits and there was an osseous fusion of the terminal phalanges of the fourth and fifth digits. She also had a cleft of the soft palate and partial syndactyly between the second and third toes of both feet. The cleft palate and syndactyly of the fingers have been corrected surgically. Her psychomotor development was normal.

On examination (aged 6 years) she was well built with a square shaped head (fig 1). Her hair was thin and sparse. She had a flat face with ocular hypotelorism and prominent epicanthic folds. The interpupillary distance was reduced $(40 \mathrm{~mm}$, 3rd centile), while the inner canthal distance was within

Received for publication 1 September 1984. Accepted for publication 12 October 1984

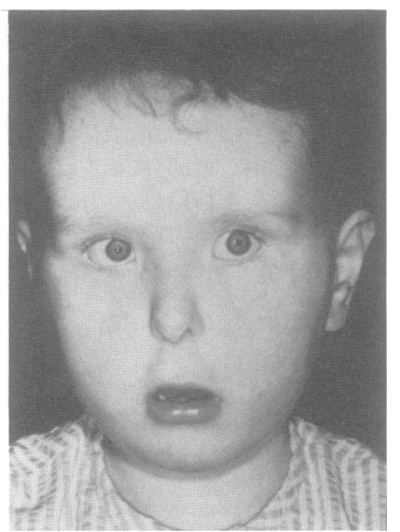

FIG 1 Facial features of case 1 at 6 years.

normal limits $(30 \mathrm{~mm}, 75$ th centile). The nose was thin with hypoplastic nasal alae and small nares. Her

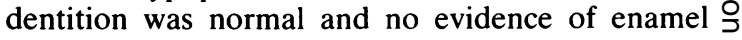
hypoplasia was found.

Ophthalmic examination revealed microphthalmos with microcornea (corneal diameter $7 \mathrm{~mm}$ ). N There was a latent convergent strabismus due to hypermetropia. There were no further ophthalmic abnormalities.

Her hearing was found to be significantly impaired owing to secretory otitis media. Myring- 0 otomy has subsequently improved her hearing.

Both parents were carefully examined and $\stackrel{\oplus}{+}$ showed no stigmata suggestive of ODD syndrome.

CASE 2

This patient was born at term after an uncompli- $\stackrel{\mathbb{D}}{\square}$ cated pregnancy. An episode of rectal bleeding 


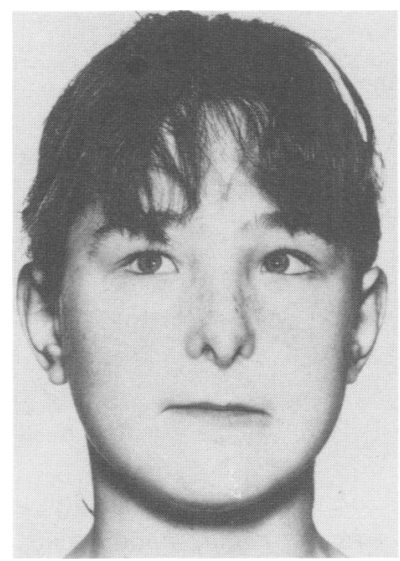

FIG 2 Facial features of case 2 at 8 years.

occurred in the neonatal period. Her psychomotor development was normal. Her father had similar features (case 3).

She was examined at 15 years of age. The head shape was normal $(\mathrm{OFC}=55 \mathrm{~cm})$. There was no abnormality of hair growth. Her facial appearance was striking (fig 2). The nose was long and thin with hypoplasia of the nasal alae, small nares, and a prominent columella. There was evidence of syndactyly of the third, fourth, and fifth fingers of both hands. The syndactyly had been corrected by plastic surgery with good functional result. Radiological examination before corrective surgery showed an osseous fusion of the terminal phalanges of the third, fourth, and fifth digits of both hands.

Ophtha:mic examination showed no abnormality of the iris, cornea, or fundus. There were prominent epicanthic folds, which gave the appearance of hypertelorism, but this was not confirmed by measurement. The interpupillary distance was 60 $\mathrm{mm}$ (80th centile) and the inner canthal distance was $35 \mathrm{~mm}$ (90th centile). Dental examination revealed small teeth with loss of enamel at the incisor tips. Dental caries was minimal.

\section{CASE 3}

This man (father of case 2) was born in 1941. He had enjoyed good health and, apart from receiving corrective surgery for syndactyly in early childhood, had not sought medical attention.

His facial appearance resembled that of his daughter (fig 3). There was a long, thin, pinched nose with hypoplasia of the nasal alae. He had evidence of soft tissue syndactyly only of the fourth and fifth digits of both hands with camptodactyly. There were no dental or ocular abnormalities.

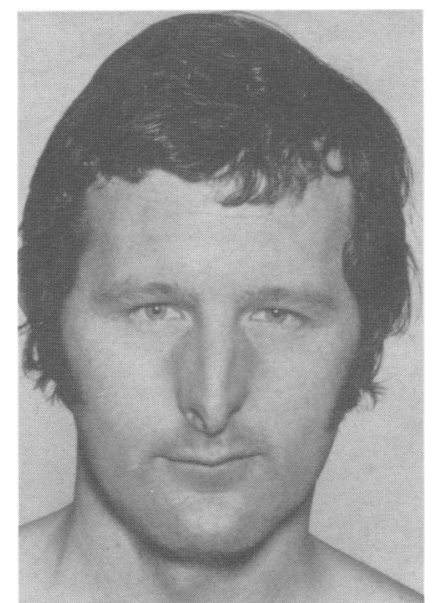

FIG 3 Facial features of case 3, father of case 2.

\section{Discussion}

The consistency of the facial appearance in all reported cases of the ODD syndrome is striking and worth stressing. The thin pinched nose with hypoplastic nasal alae and prominent columellae is well illustrated in the cases reported here. A review of the family photographs showed that these features were clearly present from infancy, but became more obvious by the fourth year of life (fig 4). Hypoplasia of the nasal alae, in the presence of other associated abnormalities, is also seen in the orofacial-digital syndrome $^{4}$ and in the Hallermann-Streiff syndrome. ${ }^{5}$ The narrow nasal bridge and prominent epicanthic folds give the impression of hypertelorism or telecanthus, but this is not always confirmed when measurements of the interpupillary and inner canthal distances are made. ${ }^{6}$ In our first case hypotelorism was found, and in the second case both distances were within the normal range. Open angle glaucoma has been reported as a late complication, but was not present in our cases. Periodic ophthalmic examination is recommended for all patients with this syndrome. $^{7}$

Syndactyly is associated with osseous fusion of the terminal phalanges and absence of the middle phalanx of the fifth digit. The defect can be corrected to give an excellent functional result.

Conductive deafness resulting from secretory otitis media was present in our first case. As she had not suffered from ear infections and had had the partial cleft palate repaired successfully, the secretory otitis media may have been a primary feature of ODD syndrome. Conductive deafness has been reported in six previous cases of ODD 


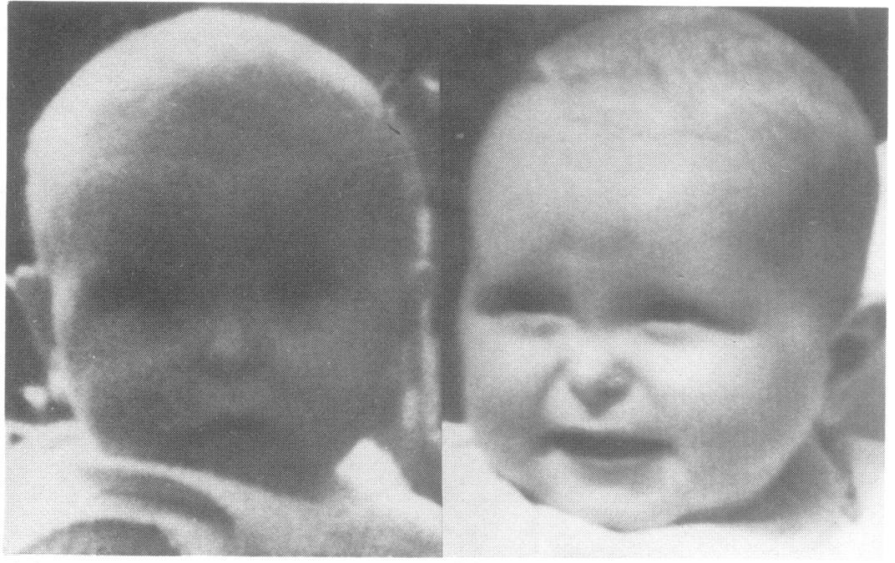

(a)

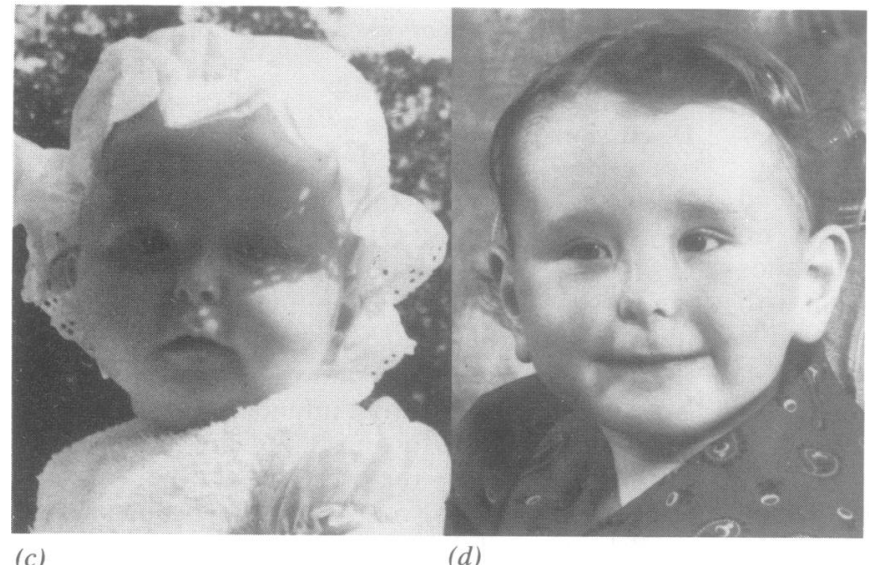

FIG 4 Family photographs of case 1 showing development of facial phenotype: (a) 5 months, (b) 9 months, (c) 2 years, (d) 4 years. syndrome,,$^{3} 4$ 7-9 12 only one of which had an associated cleft palate. ${ }^{4}$ There may be a bony abnormality in the Eustachian tube or middle ear in ODD syndrome.

The pathogenesis of this syndrome is not known. Rajic and de Veber ${ }^{10}$ outlined some features in their skeletal survey, such as undertabulation of the long bones, widening of the ribs, and hyperostosis of the calvarium, which are similar to the changes seen in a number of sclerosing skeletal dysplasias. Biopsy of the tibiae in three of their patients did show a 'pagetoid mosaic' pattern under polarised light. There was no radiological evidence of osteosclerosis in our cases.

Autosomal dominant inheritance is established with vertical transmission reported in five pedigrees, three of which have shown inheritance from father to son. ${ }^{3}$ The remaining reported cases have been sporadic and are presumably due to fresh mutations.
Jones et al $^{11}$ demonstrated that fresh gene mutations in ODD syndrome are associated with advanced paternal age. He found the mean paternal age for

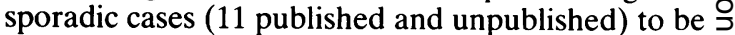
$32 \cdot 3$ years, compared with a mean paternal age in $\frac{D}{O}$ the general population of 29.3 years. In keeping with this hypothesis there is a considerable dif- $N$ ference in the paternal age in our first sporadic case (33 years) and our second paternally inherited case (24 years) in this report.

\section{References}

1 Lohmann W. Beitrag zur Kenntris des reinen mikropthalmus Arch Augenheilkd 1920;86:136-41.

${ }^{2}$ Meyer-Schwickerath G, Gruterick E, Weyers H. Microphthalmussyndrom. Klin Monatsbl Augenheilkd 1957;131:18-30.

3 Judisch GF, Martin-Casals A, Hanson JW, Olin WH. Ocu- $\frac{\rho}{\square}$ lodentodigital dysplasia: four new reports and a literature $\varrho$ review. Arch Ophthalmol 1979;97:878-84. 
${ }^{4}$ Eidelman E, Chosack A, Wagner M. Orodigitofacial dysostosis and oculodentodigital dysplasia. Oral Surg 1967:23:311-9.

${ }^{5}$ Kurlander GJ, Lavy NW, Campbell JA. Roentgen differentiation of the oculodentodigital syndrome and Hallermann Streiff syndrome in infancy. Radiology 1966;86:77-85.

${ }^{6}$ Fara M, Gorlin RJ. The question of hypertelorism in oculodentoosseous dysplasia. Am J Med Genet 1981:10:101-2.

7 Reisner SH, Kott E, Bornstein B. Salinger H, Kaplan I. Gorlin RJ. Oculodentodigital dysplasia. Am J Dis Child 1969:118:6007.

${ }^{8}$ Gillespie FD. A hereditary syndrome: dysplasia oculodentodigitalis. Arch Ophthalmol 1964:71:187-92.

${ }^{9}$ Thoden CJ, Ryoppy S. Kuntunen P. Oculodentodigital dysplasia syndrome: report of four cases. Acta Paediatr Scand 1977:66:635-8.
11 Rajic DS, de Veber LL. Hereditary oculodento osscous dysplasia. Ann Radiol 1966:9:224-31.

1 Jones KL. Smith DW. Harvey MAS. Hall BD, Quan L. Older paternal age and fresh gene mutation: data on additional disorders. J Pediatr 1975;86:84-8.

12 Gorlin RJ, Meskin LH, Gerne JW. Oculodentodigital dysplasia. J Pediatr 1963;63:69-75.

Correspondence and requests for reprints to $\mathrm{Dr}$ M A Patton, Department of Clinical Genetics, The Hospital for Sick Children, Great Ormond Street, London WC1N 3JH.

\section{Correction}

In the article 'Familial occurrence of a pseudodicentric chromosome 21' by Hancke and Miller ( $J$ Med Genet 1985;22:155-6), we regret that a chromosome was missing from fig 1a. The full, correct figure is printed below.

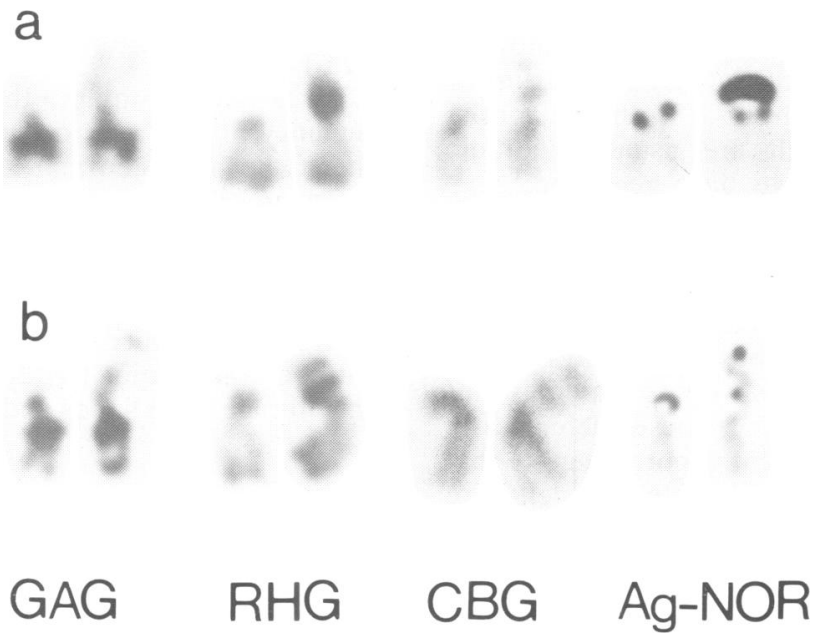

